\title{
Effects of Homogenization Annealing on Dynamic Recrystallization in Mg-Al-Ca-RE (Rare Earth) Alloy
}

\author{
Masataka Hakamada ${ }^{1}$, Akira Watazu ${ }^{1}$, Naobumi Saito ${ }^{1}$ and Hajime Iwasaki ${ }^{2}$ \\ ${ }^{1}$ Materials Research Institute for Sustainable Development, National Institute of Advanced Industrial Science and Technology, \\ Nagoya 463-8560, Japan \\ ${ }^{2}$ The Materials Process Technology Center, Tokyo 105-0011, Japan
}

Compression tests were conducted at the temperature of $573 \mathrm{~K}$ with the true strain rates of $10^{-3}-1 \mathrm{~s}^{-1}$ on as-cast and homogenized Mg6Al-2Ca-2RE (RE = rare earth) (in mass\%) alloy specimens, and their dynamic recrystallization (DRX) behaviors were investigated. Strain hardening occurred after yielding, followed by strain softening. The flow stress of the as-cast specimen was higher than that of the homogenized specimen. The DRX grain size depended minimally on the Z-parameter in both of the as-cast and homogenized specimens. This is likely to be due to the particle-stimulated nucleation mechanism involving the second-phase particles. When the specimens were deformed to the true compressive strain of 1.6, non-recrystallized regions were not observed in the homogenized specimen; however, they were partially observed in the as-cast specimen. The grain size in the recrystallized region in the as-cast specimen was smaller than that in the homogenized specimen. Elemental analyses revealed $\mathrm{Al}$ segregation around the second-phase particles in the as-cast specimen. Therefore, it is suggested that DRX in the present $\mathrm{Mg}-\mathrm{Al}-\mathrm{Ca}-\mathrm{RE}$ alloy is affected by not only the second-phase particles, but also the Al segregation.

[doi:10.2320/matertrans.MC200783]

(Received October 5, 2007; Accepted November 22, 2007; Published April 25, 2008)

Keywords: magnesium alloy, second-phase particle, dynamic recrystallization, compression test, segregation

\section{Introduction}

Mg alloys have high potential for improving fuel efficiency and reduction in $\mathrm{CO}_{2}$ emission because of their high specific strength and stiffness. ${ }^{1)}$ For more applications of $\mathrm{Mg}$ alloys, it is desirable to improve creep resistance because $\mathrm{Mg}$ alloys often show poor creep resistance. Although the addition of a rare earth metal (RE) such as Ce improves the creep resistance of $\mathrm{Mg}$ alloys, ${ }^{2-7)} \mathrm{RE}$ is expensive. Recently, it has been reported that $\mathrm{Mg}$ alloys containing $\mathrm{Ca}$ show high creep resistance and elevated temperature strength. ${ }^{8-12)}$ Indeed, $\mathrm{Ca}$ is an effective fire retardant. ${ }^{13)}$ For commercial applications, $\mathrm{Ca}$ is a desirable additional element to $\mathrm{Mg}$ because of its lower cost than that of RE.

Insoluble second-phases such as $\mathrm{Al}_{2} \mathrm{Ca}$ and $\mathrm{Mg}_{2} \mathrm{Ca}$ are often formed in Mg-Al-Ca system alloys. Such secondphases enhance dynamic recrystallization (DRX) by the particle-stimulated nucleation (PSN) mechanism. ${ }^{14,15)} \mathrm{Re}$ cently, it has been shown that Mg-Al-Ca-RE alloy exhibits unique DRX behavior because the second-phase particles play an important role in DRX. ${ }^{16)}$ Recrystallization behavior is influenced by the presence of not only second-phase particles but also solutes, because deformation mechanisms are affected by solutes. ${ }^{17-19)}$ In the present paper, we describe the effects of homogenization annealing on DRX in Mg-6Al$2 \mathrm{Ca}-2 \mathrm{RE}$ (in mass\%) alloy. Compression tests are conducted at the temperature of $573 \mathrm{~K}$ with the true strain rate of $10^{-3}$ $1 \mathrm{~s}^{-1}$ on as-cast and homogenized specimens, and their DRX behaviors are investigated.

\section{Experimental Procedure}

A Mg-6Al-2Ca-2RE (in mass\%) alloy ingot was prepared by die-casting (Mitsui Mining \& Smelting Co., Ltd.). The chemical composition of the alloy is shown in Table 1. Homogenization annealing was carried out on some alloy
Table 1 Chemical composition of Mg-6Al-2Ca-2RE (in mass\%) alloy.

\begin{tabular}{cccccccccc}
\hline $\mathrm{Al}$ & $\mathrm{Zn}$ & $\mathrm{Mn}$ & $\mathrm{RE}$ & $\mathrm{Ca}$ & $\mathrm{Fe}$ & $\mathrm{Cu}$ & $\mathrm{Si}$ & $\mathrm{Ni}$ & $\mathrm{Mg}$ \\
\hline 6.4 & 0.01 & 0.23 & 2.3 & 2.2 & $<0.004$ & $<0.004$ & $<0.08$ & $<0.001$ & Balance
\end{tabular}

ingots at $683 \mathrm{~K}$ for 108 hours. A series of microstructural observations and elemental analyses were performed with an optical microscope, a scanning electron microscope with a wavelength-dispersive X-ray spectrometer (SEM-WDX) and a scanning transmission electron microscope with an energy dispersive X-ray spectrometer (STEM-EDX).

The cylindrical specimens with dimensions of $10 \mathrm{~mm}$ in diameter and $12 \mathrm{~mm}$ in height were cut for compression tests. The compression tests were carried out at the temperature of $573 \mathrm{~K}$ with constant true strain rates of $10^{-3}-1 \mathrm{~s}^{-1}$ using a servohydraulic testing machine. The microstructure of the deformed specimens was investigated using an optical microscope. The plane observed with the optical microscope was parallel to the compressive direction. The grain sizes were measured by the line intercept method $(d=1.74 L$, where $d$ and $L$ are the grain size and the line intercept length, respectively).

\section{Results}

Microstructures of the as-cast and homogenized specimens are shown in Fig. 1. Many second-phase particles were present mainly at the grain boundaries. The STEM-EDX results suggested that the second-phase particles were mainly composed of $\mathrm{Al}, \mathrm{Ca}, \mathrm{La}$ and $\mathrm{Ce}$, as will be shown later (Figs. 7 and 8). The distribution of the second-phase particles was not varied by the homogenization annealing. Grain growth was negligible during the homogenization annealing and grain sizes were approximately $20 \mu \mathrm{m}$ for both types of specimens. 

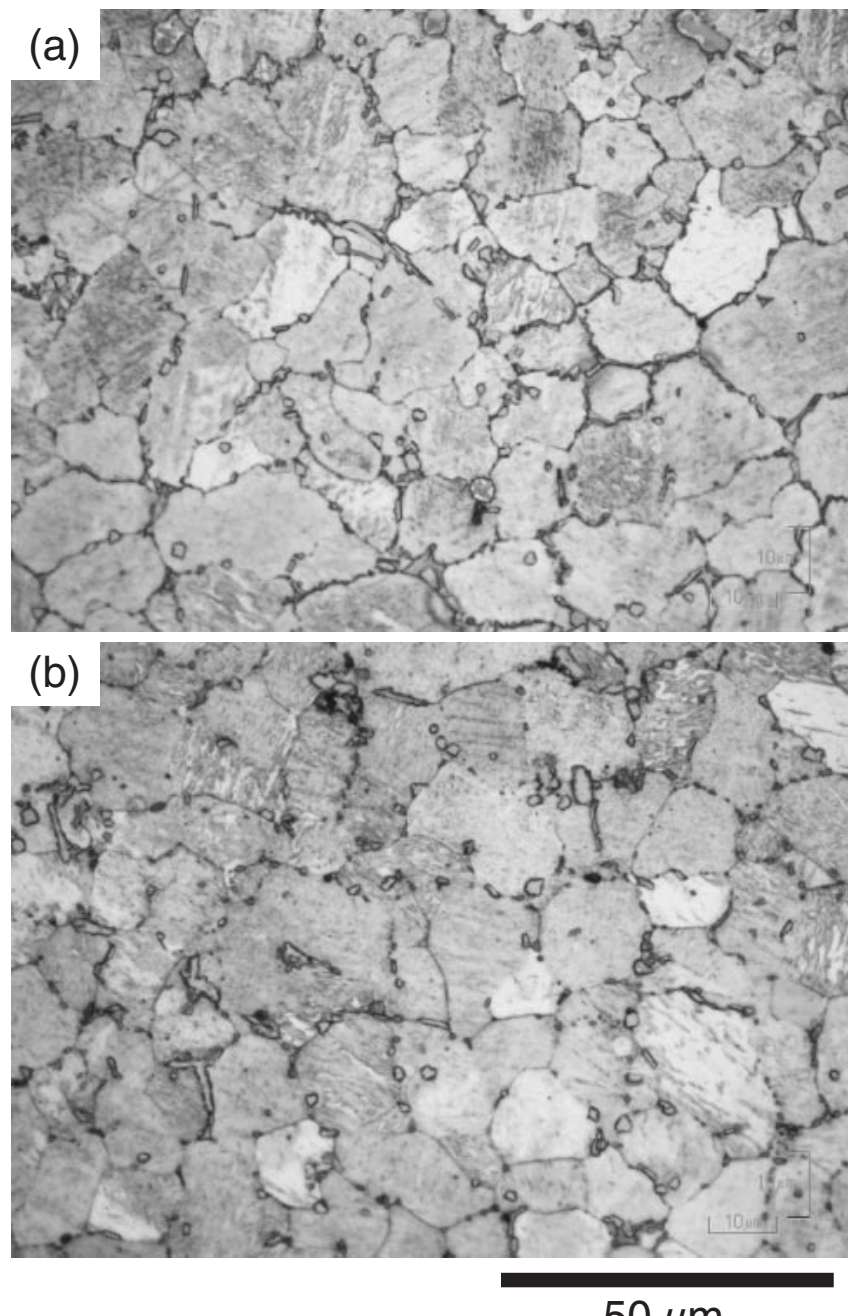

$50 \mu \mathrm{m}$

Fig. 1 Microstructures of (a) as-cast and (b) homogenized Mg-6Al-2Ca2RE (in mass\%) alloy specimens prior to compression tests.

The true compressive stress-strain curves at $573 \mathrm{~K}$ with strain rates of $10^{-3}-1 \mathrm{~s}^{-1}$ for the as-cast and homogenized specimens are shown in Fig. 2, assuming that deformation is uniform. Strain hardening occurred after yielding, and then strain softening was observed, following a nearly constant flow stress state. This trend was obtained under all testing conditions investigated. The occurrence of the strain softening suggests that DRX occurred during compression, irrespective of homogenization annealing. The flow stress for the homogenized specimen was lower than that for the as-cast specimen under the same testing conditions, except at strain $>1$ with the strain rate of $10^{-3} \mathrm{~s}^{-1}$.

Microstructures of the specimens deformed to true compressive strain $\varepsilon=1.6$ at $573 \mathrm{~K}$ with strain rates of $10^{-3}$ and $1 \mathrm{~s}^{-1}$ for the as-cast and homogenized specimens are shown in Fig. 3. DRX occurred, but non-recrystallized regions partially remained in the as-cast specimen ((a) and (b) in Fig. 3). Such a mixture of recrystallized and the nonrecrystallized regions has been observed in the previous studies. $^{20-24)}$ On the other hand, DRX was complete and non-recrystallized regions were not observed in the homogenized specimens ((c) and (d) in Fig. 3). Inspection of Fig. 3 reveals that the grain size in the recrystallized region in the
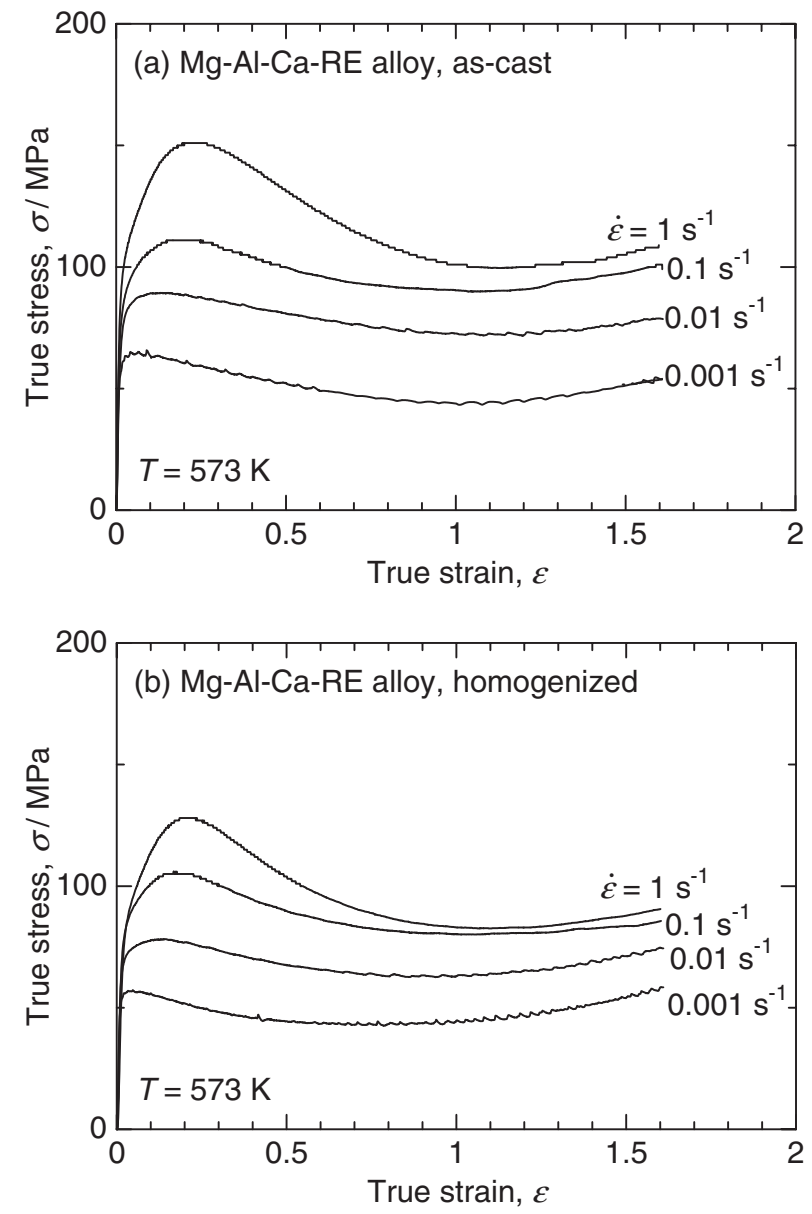

Fig. 2 True compressive stress-strain curves at $573 \mathrm{~K}$ with strain rates of $10^{-3}-1 \mathrm{~s}^{-1}$ for (a) as-cast and (b) homogenized specimens.

as-cast specimen is smaller than that in the homogenized specimen.

The average grain sizes in the recrystallized region for the as-cast specimen deformed to $\varepsilon=1.6$ at $573 \mathrm{~K}$ were $3.2 \mu \mathrm{m}$ at the strain rate of $10^{-3} \mathrm{~s}^{-1}, 3.8 \mu \mathrm{m}$ at $10^{-2} \mathrm{~s}^{-1}, 4.5 \mu \mathrm{m}$ at $10^{-1} \mathrm{~s}^{-1}$ and $6.3 \mu \mathrm{m}$ at $1 \mathrm{~s}^{-1}$. The recrystallized grain size slightly decreased as the strain rate increased. On the other hand, those for the homogenized specimen deformed to $\varepsilon=$ 1.6 at $573 \mathrm{~K}$ were $8.8 \mu \mathrm{m}$ at $10^{-3} \mathrm{~s}^{-1}, 6.7 \mu \mathrm{m}$ at $10^{-2} \mathrm{~s}^{-1}$, $7.1 \mu \mathrm{m}$ at $10^{-1} \mathrm{~s}^{-1}$ and $7.1 \mu \mathrm{m}$ at $1 \mathrm{~s}^{-1}$. Thus, the effect of the stain rate on the DRX grain size was greater in the as-cast specimen than in the homogenized specimen.

The second-phase particles were dispersed during the hot compression and particles $<3 \mu \mathrm{m}$ in diameter were observed in the deformed specimens. Many particles were located at the grain boundaries, but some were observed in the grains. It seemed that the distribution and size of the second-phase particles in the as-cast specimen were similar to those in the homogenized specimen.

In continuous DRX, the recrystallized grain size of $\mathrm{Mg}$ alloys is governed by the Z-parameter $(=\dot{\varepsilon} \exp (Q / R T)),{ }^{25-28)}$ where $\dot{\varepsilon}$ is the strain rate, $Q$ is the activation energy for dominant diffusion, $T$ is the absolute temperature and $R$ is the gas constant, and the DRX grain size can be given by

$$
d^{*} \propto Z^{-p}
$$



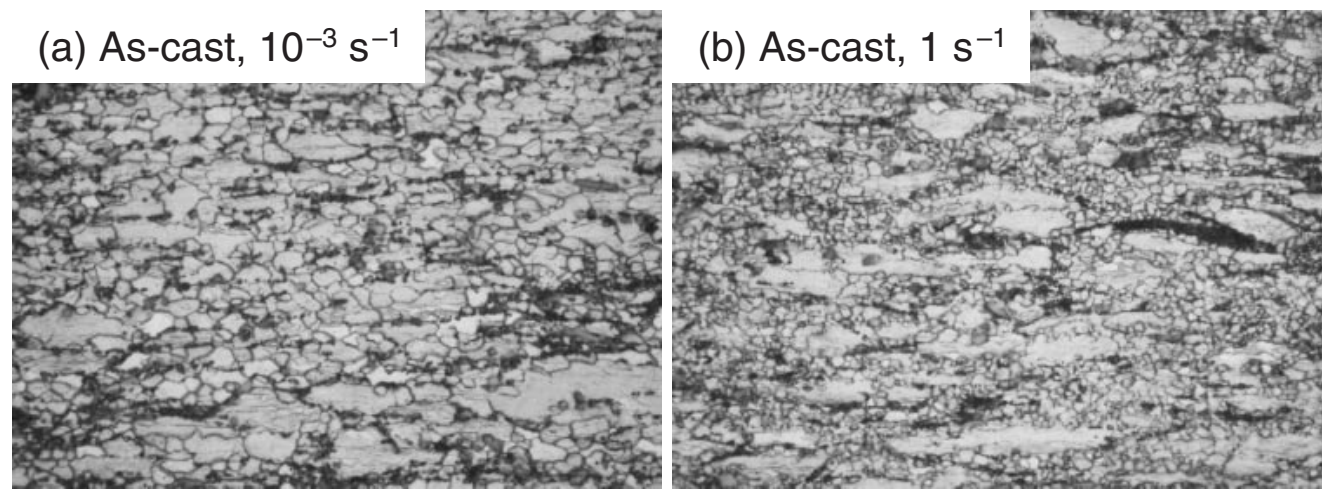

(c) Homogenized, $10^{-3} \mathrm{~s}^{-1}$
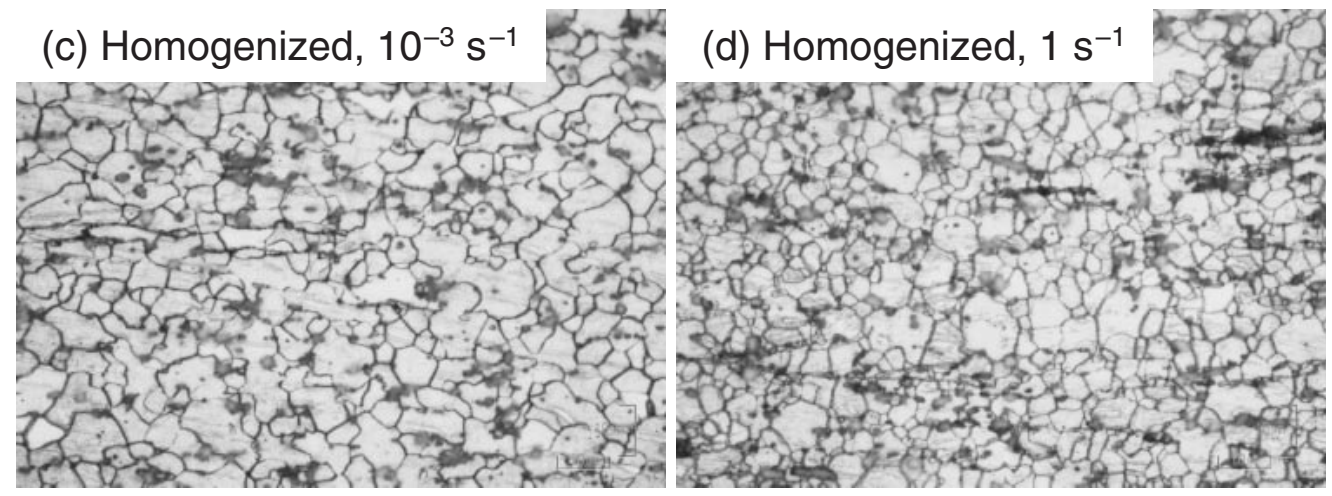

$50 \mu \mathrm{m}$

Fig. 3 Microstructures of specimens deformed to $\varepsilon=1.6$ at $573 \mathrm{~K}$. (a) As-cast specimen deformed at strain rate of $10^{-3} \mathrm{~s}^{-1}$. (b) As-cast specimen deformed at strain rate of $1 \mathrm{~s}^{-1}$. (c) Homogenized specimen deformed at strain rate of $10^{-3} \mathrm{~s}^{-1}$. (d) Homogenized specimen deformed at strain rate of $1 \mathrm{~s}^{-1}$.

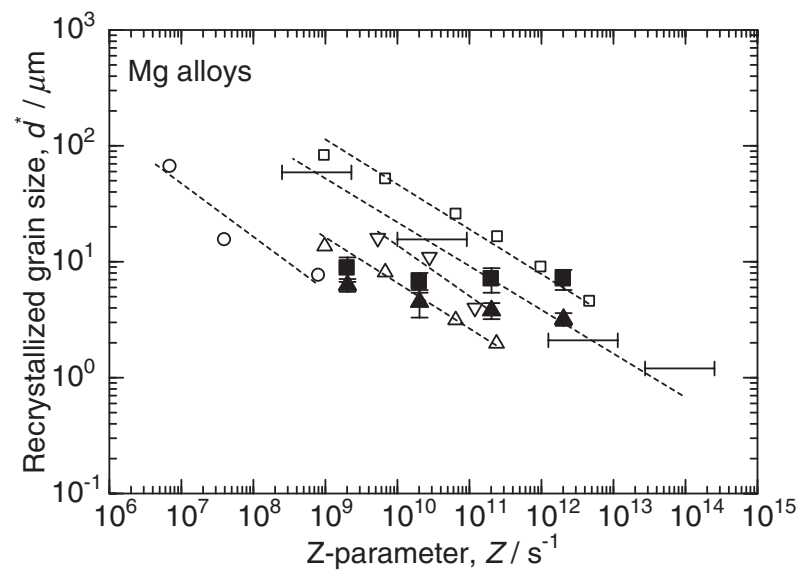

\begin{tabular}{|ll|}
\hline & AZ91 (Ref. 25) \\
$\triangle$ & AZ61 (Ref. 26) \\
$\square$ & AZ31 (Ref. 26) \\
$\longmapsto$ & AZ91 (Ref. 27) \\
$\nabla$ & AZ91 (Ref. 28) \\
$\Delta$ & Present (As-cast) \\
$\square$ & Present (Homogenized)
\end{tabular}

Fig. 4 Variation in recrystallized grain size as a function of Z-parameter for the present and reported data.

where $d^{*}$ is the recrystallized grain size, $Z$ is the Z-parameter and $p$ is the grain size exponent. The variation in recrystallized grain size as a function of Z-parameter for $\mathrm{Mg}$ alloys is shown in Fig. 4, assuming that the activation energy is the same as that for the lattice diffusion of $\mathrm{Mg}(135 \mathrm{~kJ} / \mathrm{mol}){ }^{29)}$

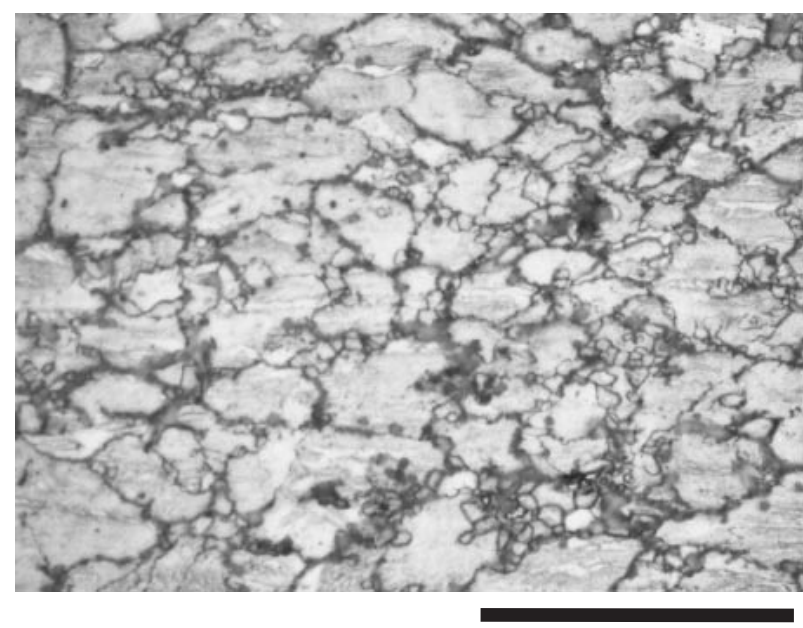

$50 \mu \mathrm{m}$

Fig. 5 Microstructure of as-cast specimen deformed to $\varepsilon=0.35$ at $573 \mathrm{~K}$ with strain rate of $1 \mathrm{~s}^{-1}$.

For comparison, the data of Mg-Al-Zn system alloys are superimposed in Fig. 4..$^{25-28)}$ The DRX grain size decreased with increasing Z-parameter and $p$ was $0.2-0.4$ in the Mg-Al$\mathrm{Zn}$ alloys. However, the Z-parameter dependence of recrystallized grain size was much lower in both the as-cast and homogenized specimens of the present Mg-Al-Ca-RE alloy than in the Mg-Al-Zn alloys. Therefore, it is suggested that the fundamental DRX mechanism in the as-cast specimen is the same as that in the homogenized specimen. 


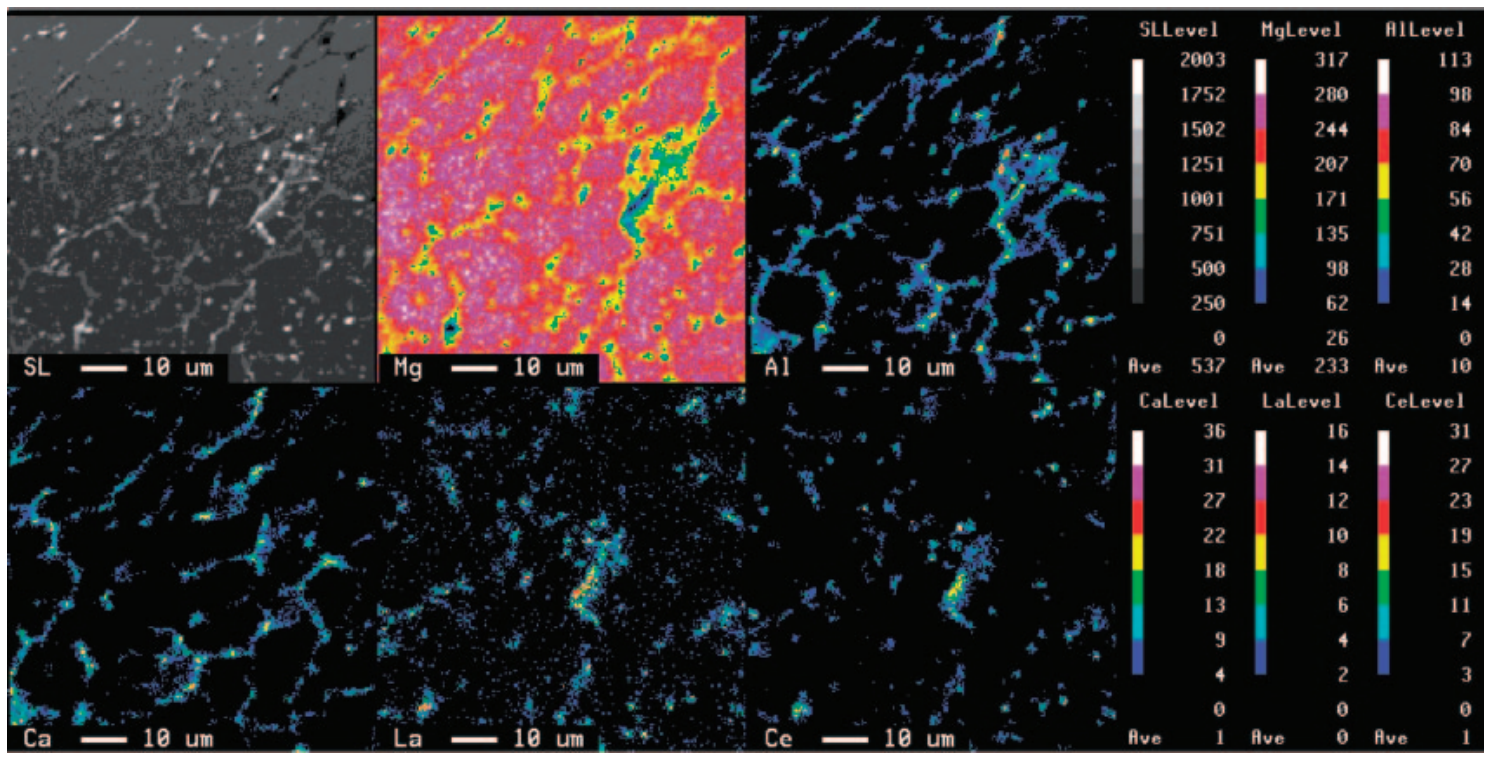

\section{(b) Homogenized}

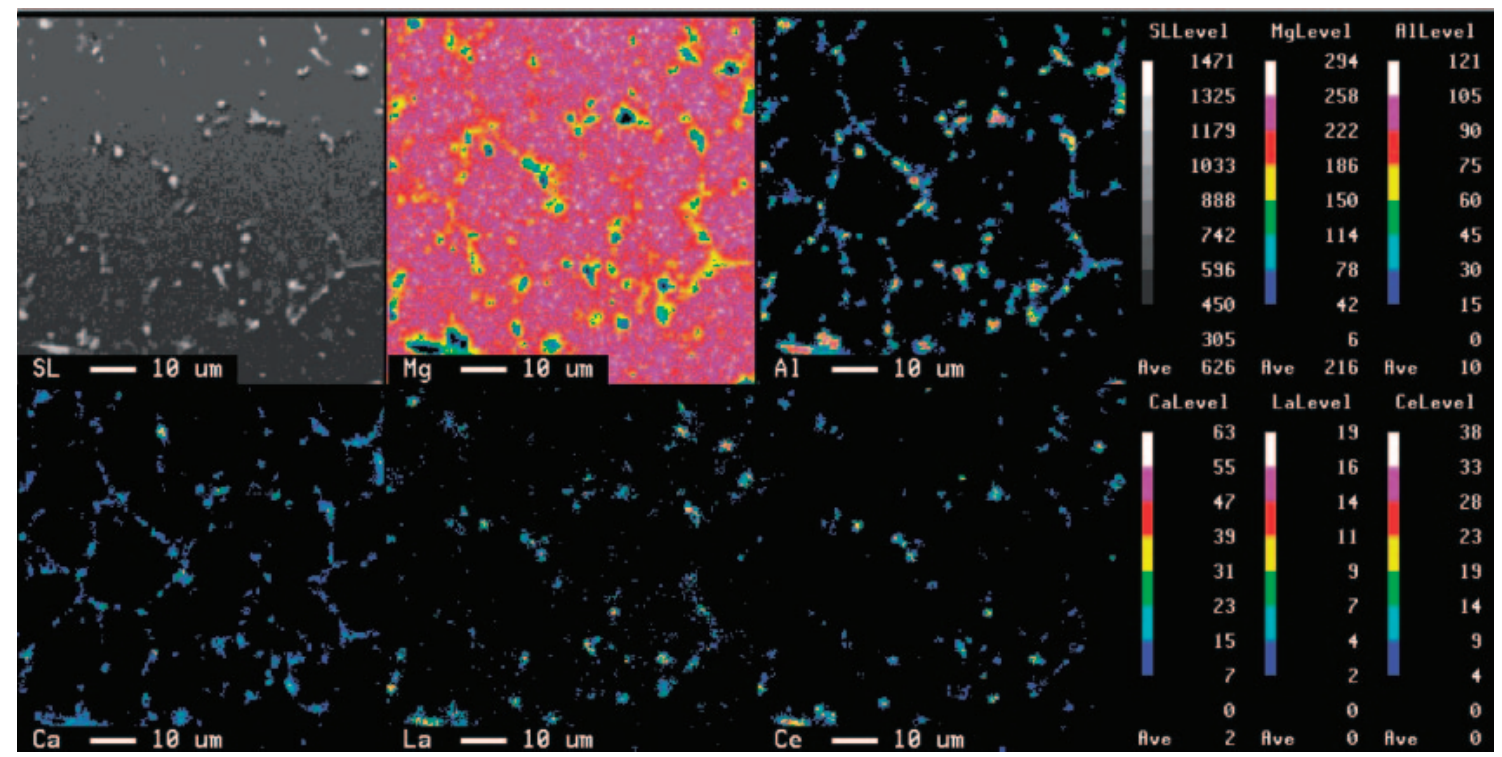

Fig. 6 Elemental mapping of (a) as-cast and (b) homogenized specimens, obtained using SEM-WDX.

The microstructure of the as-cast specimen deformed to $\varepsilon=0.35$ at $573 \mathrm{~K}$ with the strain rate of $1 \mathrm{~s}^{-1}$ is shown in Fig. 5. Small recrystallized grains were observed preferentially around the particles in the as-cast specimen. This trend is the same as that in the homogenized specimen. ${ }^{16)}$ The origin of DRX in Mg-Al-Ca-RE alloy should be thus the PSN mechanism. ${ }^{16)}$ Therefore, it is likely that DRX due to PSN occurred in both the as-cast and homogenized specimens, irrespective of the homogenization annealing.

\section{Discussion}

The Mg-Al-Ca-RE alloy showed unique DRX behavior, namely, the DRX grain size was almost independent of the Zparameter. This is because DRX was enhanced by the PSN mechanism involving the second-phase particles. ${ }^{16)}$ How- ever, it is worthwhile to note that there are critical differences between the as-cast and homogenized specimens: (1) higher flow stress of the former, (2) smaller DRX grain size of the former, and (3) mixture of recrystallized and non-recrystallized regions in the former. In the case of the mixture of the fine-grain regions and coarse-grain regions, grain boundary sliding is much more pronounced in the fine grain region. ${ }^{30)}$ Hence, the flow stress of the as-cast specimen is expected to be lower owing to grain boundary sliding. However, the ascast specimen showed a higher flow stress than the homogenized specimen. This cannot be explained by DRX due to PSN.

The SEM-WDX elemental mappings for the as-cast and homogenized specimens are shown in Fig. 6. Al, Ca, La and Ce elements were clearly present in and around the secondphase particles in both specimens. No distinct change in the 


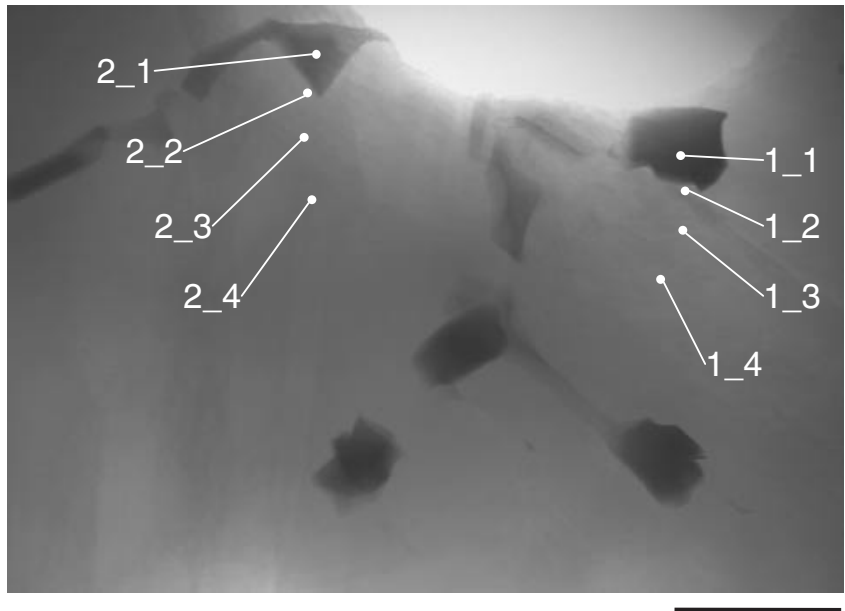

$3 \mu \mathrm{m}$

Fig. 7 Scanning transmission electron micrograph of as-cast specimen. Results of elemental analyses are listed in Table 2.

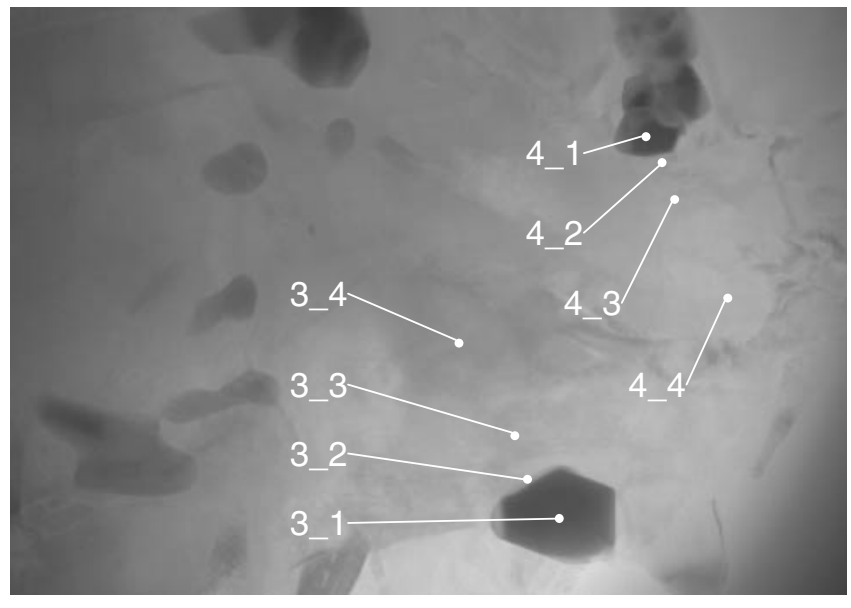

$3 \mu \mathrm{m}$

Fig. 8 Scanning transmission electron micrograph of homogenized specimen. Results of elemental analyses are listed in Table 3.

distribution of the additional elements upon homogenization annealing was detected, at least by the SEM-WDX analyses.

Transmission electron micrographs of the as-cast and homogenized specimens are shown in Figs. 7 and 8, respectively. The elementary analyses at some locations in Figs. 7 and 8 were carried out by EDX. The results are summarized in Tables 2 and 3. The $\mathrm{Ce}$ and La concentrations were $0-0.1$ at $\%$ at the positions around the second-phase particles, as well as at the positions far from the second-phase particles, in both specimens. The analytical accuracy limitation of the EDX is 0.1 at\%. Hence, changes in $\mathrm{Ce}$ and $\mathrm{La}$ concentrations upon homogenization annealing are less than the analytical accuracy limitation. On the other hand, the segregation of $\mathrm{Al}$ was observed around the second-phase particles in the as-cast specimen, but such $\mathrm{Al}$ segregation was not detected and the $\mathrm{Al}$ concentration was relatively uniform in the $\mathrm{Mg}$ matrix in the homogenized specimen. Thus, the annealing homogenized the $\mathrm{Al}$ concentration.
Table 2 Results of elemental analyses using STEM-EDX for as-cast specimen shown in Fig. 7.

\begin{tabular}{crrrrr}
\hline \multirow{2}{*}{ EDX point } & \multicolumn{5}{c}{ Concentration (at\%) } \\
\cline { 2 - 6 } & $\mathrm{Mg}$ & $\mathrm{Al}$ & $\mathrm{Ca}$ & $\mathrm{La}$ & $\mathrm{Ce}$ \\
\hline $1 \_1$ & 10.0 & 42.0 & 1.4 & 12.1 & 34.5 \\
$1 \_2$ & 97.5 & 2.3 & 0.0 & 0.1 & 0.1 \\
$1 \_3$ & 99.0 & 0.9 & 0.0 & 0.1 & 0.0 \\
$1 \_4$ & 99.3 & 0.7 & 0.0 & 0.0 & 0.0 \\
$2 \_1$ & 53.2 & 24.6 & 8.1 & 7.2 & 7.0 \\
$2 \_2$ & 98.4 & 1.5 & 0.0 & 0.0 & 0.0 \\
$2 \_3$ & 98.8 & 1.1 & 0.0 & 0.0 & 0.0 \\
$2 \_4$ & 99.2 & 0.8 & 0.0 & 0.0 & 0.0 \\
\hline
\end{tabular}

Table 3 Results of elemental analyses using STEM-EDX for homogenized specimen shown in Fig. 8.

\begin{tabular}{crrrrr}
\hline \multirow{2}{*}{ EDX point } & \multicolumn{5}{c}{ Concentration (at\%) } \\
\cline { 2 - 6 } & $\mathrm{Mg}$ & \multicolumn{1}{c}{$\mathrm{Al}$} & $\mathrm{Ca}$ & \multicolumn{1}{c}{$\mathrm{La}$} & $\mathrm{Ce}$ \\
\hline 3_1 & 12.3 & 40.2 & 3.1 & 13.6 & 30.8 \\
$3 \_2$ & 98.4 & 1.4 & 0.0 & 0.1 & 0.0 \\
$3 \_3$ & 98.4 & 1.5 & 0.0 & 0.1 & 0.0 \\
$3 \_4$ & 98.7 & 1.3 & 0.0 & 0.0 & 0.0 \\
$4 \_1$ & 11.5 & 40.2 & 11.3 & 15.3 & 21.8 \\
$4 \_2$ & 98.8 & 1.0 & 0.1 & 0.1 & 0.0 \\
$4 \_3$ & 98.9 & 1.0 & 0.0 & 0.0 & 0.0 \\
$4 \_4$ & 98.8 & 1.2 & 0.0 & 0.0 & 0.0 \\
\hline
\end{tabular}

It can be accepted that DRX behavior depends on the stacking fault energy; namely, DRX tends to occur more easily in metals with lower stacking fault energy. ${ }^{28)}$ The stacking fault energy is affected by the solute concentration. In particular, the stacking fault energy of $\mathrm{Mg}$ alloys decreases with increasing $\mathrm{Al}$ concentration. ${ }^{31)}$ As shown in Fig. 7, the $\mathrm{Al}$ concentration was not uniform in the as-cast specimen. Such a nonuniform Al concentration distribution is likely to be responsible for the mixture of the recrystallized and nonrecrystallized regions, as well as the smaller DRX grain size, in the as-cast specimen. In addition, the $\mathrm{Al}$ segregation around the particles may serve as obstacles to grain boundary sliding, resulting in higher flow stress in the as-cast specimen in spite of the smaller grain size. Therefore, it is suggested that the DRX behavior in the Mg-Al-Ca-RE alloy is affected by not only the second-phase particles but also the solute-Al segregation.

Another possible reason for the higher flow stress in the ascast specimen is the lower degree of randomization in the crystal texture as a result of the localized DRX. That is, the texture in the homogenized specimen may be randomized during a compression because of the homogeneous DRX ${ }^{16)}$ throughout the specimen, resulting in lower flow stress in the homogenized specimen. However, the flow stress in the ascast specimen was higher even before the strain softening accompanying DRX (Fig. 2); consequently, the difference in texture variation cannot fully explain the higher flow stress in the as-cast specimen. Thus, Al segregation around the second-phase particles has a crucial influence on the DRX in the Mg-Al-Ca-RE alloy. 


\section{Conclusions}

Compression tests were conducted at $573 \mathrm{~K}$ with true strain rates of $10^{-3}-1 \mathrm{~s}^{-1}$ for as-cast and homogenized $\mathrm{Mg}-6 \mathrm{Al}-$ 2Ca-2RE (in mass\%) specimens and their DRX behaviors were investigated to clarify the effects of homogenization annealing on DRX. The results are summarized as follows.

(1) Strain hardening occurred after yielding, and then strain softening was observed, following a nearly constant stress state under all testing conditions investigated. The flow stress of the as-cast specimen was higher than that of the homogenized specimen.

(2) The DRX grain size was almost independent of the Zparameter in both the as-cast and homogenized specimens. Therefore, it is suggested that DRX occurs by the PSN mechanism involving second-phase particles for both specimens, irrespective of homogenization annealing.

(3) At $\varepsilon=1.6$, DRX was complete and non-recrystallized regions were not observed in the homogenized specimen. On the other hand, DRX occurred, but nonrecrystallized regions were partially observed in the ascast specimen. The DRX grains in the recrystallized region in the as-cast specimen were smaller than those in the homogenized specimen.

(4) Elemental analyses revealed $\mathrm{Al}$ segregation around the second-phase particles in the as-cast specimen. Therefore, it is suggested that DRX in the Mg-Al-Ca-RE alloy was affected by not only the second-phase particles, but also Al segregation.

\section{Acknowledgements}

The authors are grateful to Dr. K. Kubota of Mitsui Mining \& Smelting Co., Ltd. for supplying the Mg-Al-Ca-RE alloy ingot. This study was conducted with financial aid from the "Forged Magnesium Parts Technological Development Project" organized by the New Energy and Industrial Technology Development Organization (NEDO), Japan.

\section{REFERENCES}

1) M. Hakamada, T. Furuta, Y. Chino, Y. Chen, H. Kusuda and M. Mabuchi: Energy 32 (2007) 1352-1360.

2) T. E. Leontis and J. P. Murphy: Trans. AIME 166 (1946) 295-327.

3) G. A. Mellor and R. W. Ridley: J. Inst. Met. 81 (1952-1953) 245-253.

4) I. J. Polmear: Mater. Sci. Tech. 10 (1994) 1-16.

5) A. Luo and M. O. Pekguleryuz: J. Mater. Sci. 29 (1994) 5259-5271.

6) B. R. Powell, V. Rezhets, M. P. Balogh and R. A. Waldo: JOM 54 (2002) 34-38.

7) B. L. Mordike: Mater. Sci. Eng. A 324 (2002) 103-112.

8) R. Nimoniya, T. Ojiro and K. Kubota: Acta Metall. Mater. 43 (1995) 669-674.

9) A. A. Luo, M. P. Balogh and B. R. Powell: Metall. Mater. Trans. A 33A (2002) 567-574.

10) Y. Chino, M. Kobata, H. Iwasaki and M. Mabuchi: Mater. Trans. 43 (2002) 2643-2646.

11) K. Ozturk, Y. Zhong, A. A. Luo and Z.-K. Liu: JOM 55 (2003) 40-44.

12) K. Hirai, H. Somekawa, Y. Takigawa and K. Higashi: Mater. Sci. Eng. A 403 (2005) 276-280.

13) S. Akiyama, H. Ueno, M. Sakamoto, H. Hirai and A. Kitahara: Materia Japan 39 (2000) 72-74.

14) F. J. Humphreys: Mater. Sci. Eng. A 135 (1991) 267-273.

15) F. J. Humphreys: Acta Metall. 25 (1977) 1323-1344.

16) M. Hakamada, A. Watazu, N. Saito and H. Iwasaki: to be published.

17) A. Akhtar and E. Teghtsoonian: Acta Metall. 17 (1969) 1339-1349.

18) C. H. Cáceres and D. M. Rovera: J. Light Met. 1 (2001) 151-156.

19) S. R. Agnew, M. H. Yoo and C. N. Tomé: Acta Mater. 49 (2001) 42774289.

20) S. E. Ion, F. J. Humphreys and S. H. White: Acta Metall. 30 (1982) 1909-1919.

21) N. G. Zaripov, A. R. Vagapov and R. O. Kaybyshev: Phys. Met. Metall. 63 (1987) 139-146.

22) R. O. Kaibyshev and O. Sh. Sitdikov: Phys. Met. Metall. 73 (1992) 635-642.

23) O. Sitdikov and R. Kaibyshev: Mater. Trans. 42 (2001) 1928-1937.

24) H. S. Yang, M. G. Zelin, R. Z. Valiev and A. K. Mukherjee: Mater. Sci. Eng. A 158 (1992) 167-175.

25) M. Mabuchi, K. Kubota and K. Higashi: Mater. Trans. JIM 36 (1995) 1249-1254.

26) H. Watanabe, H. Tsutsui, T. Mukai, K. Ishikawa, Y. Okanda, M. Kohzu and K. Higashi: Mater. Trans. 42 (2001) 1200-1205.

27) M. Mabuchi, Y. Chino, H. Iwasaki, T. Aizawa and K. Higashi: Mater. Trans. 42 (2001) 1182-1189.

28) N. V. R. Kumar, J. J. Blandin, C. Desrayaud, F. Montheillet and M. Suéry: Mater. Sci. Eng. A 359 (2003) 150-157.

29) H. J. Frost and M. F. Ashby: Deformation-Mechanism Maps, (Pergamon Press, Oxford, 1982) p. 44.

30) H. Watanabe, H. Hosokawa, T. Mukai and T. Aizawa: Materia Japan 39 (2000) 347-354.

31) H. Somekawa, K. Hirai, H. Watanabe, Y. Takigawa and K. Higashi: Mater. Sci. Eng. A 407 (2005) 53-61. 